\title{
A long-term satellite study of aerosol effects on convective clouds in Nordic background air
}

\author{
M. K. Sporre ${ }^{1}$, E. Swietlicki ${ }^{1}$, P. Glantz ${ }^{2}$, and M. Kulmala ${ }^{3}$ \\ ${ }^{1}$ Department of Physics, Lund University, Box 118, 22211, Lund, Sweden \\ ${ }^{2}$ Department of Applied Environmental Science, Stockholm University, 11418, Stockholm, Sweden \\ ${ }^{3}$ Department of Physics, University of Helsinki, Post Office Box 64, 00014 Helsinki, Finland
}

Correspondence to: M. K. Sporre (moa.sporre@ nuclear.lu.se)

Received: 3 April 2013 - Published in Atmos. Chem. Phys. Discuss.: 24 May 2013

Revised: 20 January 2014 - Accepted: 27 January 2014 - Published: 28 February 2014

\begin{abstract}
Aerosol-cloud interactions constitute a major uncertainty in future climate predictions. This study combines 10 years of ground-based aerosol particle measurements from two Nordic background stations (Vavihill and Hyytiälä) with MODIS (Moderate Resolution Imaging Spectroradiometer) satellite data of convective clouds. The merged data are used to examine how aerosols affect cloud droplet sizes and precipitation from convective clouds over the Nordic countries. From the satellite scenes, vertical profiles of cloud droplet effective radius $\left(r_{\mathrm{e}}\right)$ are created by plotting retrieved cloud top $r_{\mathrm{e}}$ against cloud top temperature for the clouds in a given satellite scene. The profiles have been divided according to aerosol number concentrations but also meteorological reanalysis parameters from the ECMWF (European Centre for Medium-Range Forecasts). Furthermore, weather radar data from the BALTEX (Baltic Sea Experiment) and precipitation data from several ground-based meteorological measurement stations have been investigated to determine whether aerosols affect precipitation intensity and amount.

Small $r_{\mathrm{e}}$ throughout the entire cloud profiles is associated with high aerosol number concentrations at both stations. However, aerosol number concentrations seem to affect neither the cloud optical thickness nor the vertical extent of the clouds in this study. Cloud profiles with no or little precipitation have smaller droplets than those with more precipitation. Moreover, the amount of precipitation that reaches the ground is affected by meteorological conditions such as the vertical extent of the clouds, the atmospheric instability and the relative humidity in the lower atmosphere rather than the aerosol number concentration. However, lower precipitation
\end{abstract}

rates are associated with higher aerosol number concentrations for clouds with similar vertical extent. The combination of these ground-based and remote-sensing datasets provides a unique long-term study of the effects of aerosols on convective clouds over the Nordic countries.

\section{Introduction}

That aerosol particles have the ability to affect clouds has been known for several decades (Twomey, 1974). However, the magnitudes of the multiple effects and the exact mechanisms of how aerosols affect clouds are still associated with large uncertainties, as well as how much these processes affect global climate. Aerosols in the atmosphere can also affect the climate through scattering and absorption of incoming solar radiation and to a minor degree by influencing outgoing thermal radiation. This is called the direct aerosol effect, while anthropogenic aerosol effects on climate through interactions with clouds has been named the indirect effect (Lohmann and Feichter, 2005). The latter includes increased cloud albedo due to smaller but more numerous droplets (Twomey, 1974), suppression of drizzle, increased cloud lifetime (Albrecht, 1989), increased cloud height (Pincus and Baker, 1994) and semi-direct effects (Hansen et al., 1997). Furthermore, previous studies have revealed various aerosol effects on clouds depending on cloud type and meteorological conditions (e.g. Khain et al., 2008; Fan et al., 2009; Lee et al., 2010).

Convective clouds are important for the global climate and hydrological cycle since they transport large amounts of 
energy vertically and produce intense precipitation. The influence of aerosols on convective clouds has been studied in several different manners. For example, numerous modelling studies on aerosol interactions with convective clouds have been performed. Ekman et al. (2007) used a model with an explicit aerosol module and found that an increase in cloud condensation nuclei $(\mathrm{CCN})$ concentrations decreases the precipitation rates and that ice nuclei (IN) has a substantial effect on the development of convective clouds. Furthermore, Fan et al. (2009) found that vertical wind shear determine whether aerosols enhance convective strength or not. In another study, Khain et al. (2005) found that increased levels of CCN delay the onset of precipitation from the convective clouds and that this in turn affects the dynamics of the clouds, in particular the vertical wind velocity. Whether aerosols suppress or enhance precipitation has also been found to depend on the relative humidity (RH) of the air near cloud base (Khain et al., 2008). Lee et al. (2010) on the other hand found that clouds react differently to changes in the number of $\mathrm{CCN}$ depending on the atmospheric instability.

Moreover, aircraft investigations over the Amazonian rainforest have suggested that high $\mathrm{CCN}$ concentrations suppress precipitation and increase the level to which a cloud must grow before it can produce precipitation (Andreae et al., 2004; Freud et al., 2008a).

Convective clouds have also been studied using remote sensing techniques, mainly satellite-based sensors. A study over the Amazon found that higher aerosol optical depth (AOD) was associated with increased precipitation, cloud cover and cloud depth (Lin et al., 2006). Moreover, Rosenfeld and Lensky (1998) used satellite data to obtain vertical profiles of the cloud effective radius $\left(r_{\mathrm{e}}\right)$ and found significant differences between profiles in clean and polluted conditions. Applying the same technique, Freud et al. (2008b) studied convective clouds during one summer over southern Sweden. They found that the $r_{\mathrm{e}}$ profiles were affected by $\mathrm{PM}_{0.5}$ (mass concentrations of airborne particles below $0.5 \mu \mathrm{m}$ in diameter) measured at two ground-based stations in Sweden.

The modelling studies suggest that several parameters are important for the development of convective clouds and how aerosols affect them. Different investigations have found aerosols to both enhance and suppress precipitation, while other studies suggest that whether aerosols enhance or suppress precipitation depend on meteorological conditions (Khain, 2009). The dissimilar results clearly points to the fact that clouds are very complicated systems and that more research using different methods is needed to improve our knowledge about aerosol-cloud interactions (Stevens and Feingold, 2009).

This study of convective clouds combines $10 \mathrm{yr}$ (20002009) of cloud data from the satellite based MODIS (Moderate Resolution Imaging Spectroradiometer) instruments with ground-based aerosol measurements from the stations Vavihill (southern Sweden) and SMEAR II (Hyytiälä, central Fin- land). Since both ground-based stations have extensive time series of aerosol measurements and the MODIS instruments have been in orbit for approximately a decade, a long-term study including over 600 satellite scenes could be performed. No aerosol products from MODIS are used in the study since satellite scenes containing clouds are studied and no aerosol products are produced for cloud covered pixels. Several meteorological parameters have been investigated to determine which of these affect clouds the most and also whether the influence of aerosols on clouds depends on meteorological conditions. Furthermore, weather radar and ground-based precipitation data were analysed to determine whether the precipitation intensity and amount of precipitation reaching the ground is affected by the aerosol particles. The study is performed at the mid-latitudes where the convective strength is weaker than in the tropics, where most studies of convective clouds have taken place. In addition, the aerosol number concentrations in the current study is significantly lower than in regions affected by for example biomass burning, which has also often been the focus of studies aiming to determine how convective clouds are affected by aerosols. Hence, this is a unique, long-term study of how aerosols affect convective clouds in areas with relatively low number concentrations of aerosol particles and dynamical forcing.

\section{Method and data}

\subsection{Measurement stations}

Aerosol sub-micrometer size distribution data from the EUSAAR (EUropean Supersites for Atmospheric Aerosol Research) and ACTRIS (Aerosols, Clouds, and Trace gases Research InfraStructure Network) station Vavihill (Fig. 1) located in southern Sweden $\left(56^{\circ} 01 \mathrm{~N}, 13^{\circ} 09 \mathrm{E}, 172 \mathrm{~m}\right.$ a.s.l.) has been used in the study. There are no local pollution sources close to the station, but the cities of Helsingborg, Malmö and Copenhagen are within $25-45 \mathrm{~km}$ from the station. A DMPS (Differential Mobility Particle Analyser) that measures aerosol number concentrations of particles with a diameter between 3 and $900 \mathrm{~nm}$ has been in operation at the station since 2001. The DMPS instrument and the measurement station are described in more detail in Kristensson et al. (2008). Data from a CCN counter starting May 2008 (Fors et al., 2011) have also been utilised in the study.

The second station used in this study is the Finish SMEAR II station (Hari and Kulmala, 2005) located in Hyytiälä $\left(61^{\circ} 51 \mathrm{~N}, 24^{\circ} 17 \mathrm{E}, 181 \mathrm{~m}\right.$ a.s.l.). This is also a EUSAAR and ACTRIS background station with no local sources of pollution nearby. Aerosol particle size distribution measurements (DMPS) have been ongoing since 1996 (Aalto et al., 2001), but only data from February 2000 and onward were used here since this is when the first MODIS instrument became operational. The DMPS at Hyytiälä measured particle number concentrations in the size range 3 to 


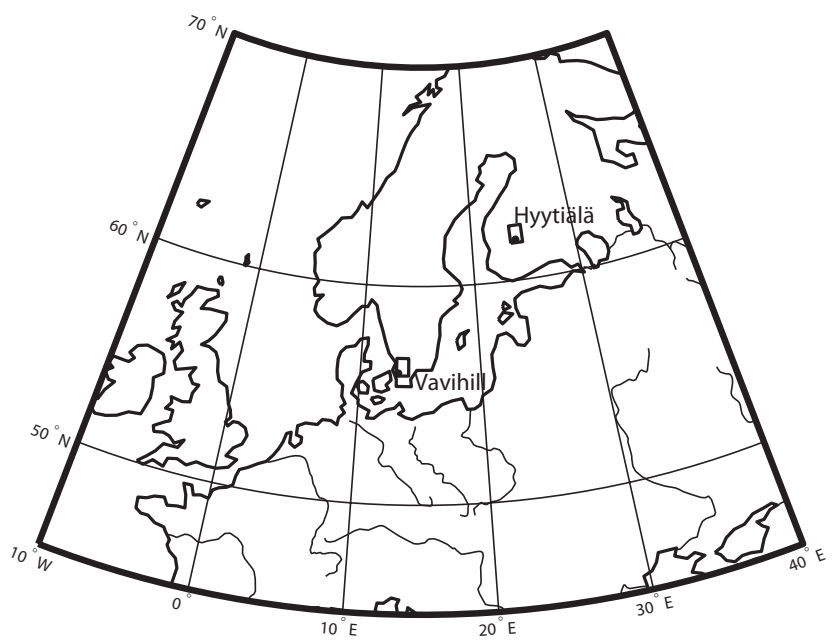

Fig. 1. Map showing the locations of the stations and the selected areas studied in the satellite images.

Table 1. Correlation coefficients between $\mathrm{CCN}$ counter data at different supersaturation and $N_{80}$.

\begin{tabular}{llllll}
\hline & $0.1 \%$ & $0.2 \%$ & $0.4 \%$ & $0.7 \%$ & $1 \%$ \\
\hline Vavihill & 0.80 & 0.92 & 0.94 & 0.88 & 0.84 \\
Hyytiälä & 0.79 & 0.92 & 0.98 & 0.97 & 0.88 \\
\hline
\end{tabular}

$500 \mathrm{~nm}$ until December 2004 when the upper limit was extended to $1000 \mathrm{~nm}$. Furthermore, the Hyytiälä CCN-counter data (Sihto et al., 2011) from June 2008 and onwards have also been utilised in this study.

Aerosol number concentrations are generally lower and have greater seasonal variability at these two Nordic stations compared to field monitoring stations in Central Europe (Asmi et al., 2011). Since CCN counter data from Vavihill and Hyytiälä was only available during less than two of the investigated years, the number of particles above $80 \mathrm{~nm}$, henceforth $N_{80}$, has been used as a proxy for CCN. This was the size range that best correlated with the cloud parameters. When $N_{80}$ is compared to the CCN data (Table 1) it best correlates (correlation coefficients: 0.94-Vavihill, 0.98Hyytiälä) at a supersaturation of $0.4 \%$, which is a reasonable value for convective clouds (Andreae, 2009).

\subsection{Satellite data}

The MODIS instruments have been in orbit onboard the Terra and Aqua satellites since 1999 and 2002, respectively. Both satellites are polar orbiting and their daytime passages over the investigated region occur sometime between morning and early afternoon local time. The MODIS instruments measure radiance at 36 spectral channels. Numerous atmospheric, cloud and aerosol parameters are calculated from the calibrated raw data and are available as Level 2 prod- ucts (King et al., 2003). In this study, both MODIS Level 1B and Level 2 Cloud Products (Platnick et al., 2003) data are utilised. From the Cloud Products, the following parameters have been used: the $r_{\mathrm{e}}$ at $3.7 \mu \mathrm{m}$, the Cloud Optical Thickness (COT), the Liquid Water Path (LWP), the Cloud Phase Optical Properties, the Cirrus Reflectance and the Multilayer Cloud Flag. The $3.7 \mu \mathrm{m} r_{\mathrm{e}}$ and not the $2.1 \mu \mathrm{m} r_{\mathrm{e}}$ has been used here since it better captures the size of the droplets at the top of the clouds, which is required in this type of study of convective clouds (Rosenfeld et al., 2004). The $3.7 \mu \mathrm{m} r_{\mathrm{e}}$ is also less sensitive to errors due to sub-pixel variability in reflectance (common for convective clouds) than the $r_{\mathrm{e}}$ at $2.1 \mu \mathrm{m}$ (Zhang et al., 2012). The MODIS Level 2 Cloud Top Temperature (CTT) is provided at $5 \mathrm{~km}$ horizontal resolution, which is too coarse to investigate convective clouds. Therefore, the Level 1B data from band $31(10.780-11.280 \mu \mathrm{m})$ and $32(11.770-12.270 \mu \mathrm{m})$ have been used to calculate the CTT at $1 \mathrm{~km}$ horizontal resolution (Rosenfeld and Lensky, 1998).

Satellite scenes were investigated for days with aerosol number size distribution data available at Vavihill or Hyytiälä. An area approximately $90 \mathrm{~km}$ by $62 \mathrm{~km}$ large (Fig. 1) was examined for each station. The boundaries for the areas are presented in Table 2. To minimise influence of surface reflectance on the cloud retrievals, the chosen areas mainly contain dense forests which provide a dark homogeneous background in the satellite scenes. The investigation of the satellite scenes was done separately for the two stations. True colour visible and COT satellite scenes over the region from both Terra and Aqua for each day with DMPS data were examined manually to find convective clouds and one satellite scene per day was chosen for days with convective clouds. Satellite scenes containing convective clouds close to frontal passages or low pressure systems were however excluded in order to ensure that only clouds fed by the boundary layer air were investigated. Furthermore, scenes recorded in late morning or early afternoon were favored, since convection typically needs several hours of daylight to develop. Also, scenes where the investigation areas were situated close to the middle of the scenes were favored since these pixels are less affected by distortions that occur at the edge of the images.

\subsection{Meteorological data and trajectory analysis}

Several meteorological parameters from the European Centre for Medium-Range Forecasts (ECMWF) were examined to investigate how meteorological conditions affect the clouds. The convective available potential energy (CAPE) has been used as a measure of the instability of the atmosphere. However, CAPE data are only available from October 2003 and hence not available for all cases included in the study. Furthermore, the vertical wind velocity at $500 \mathrm{hPa}(w)$ as well as the $\mathrm{RH}$ and specific humidity (SH) at $1000 \mathrm{hPa}$ were also included. The ECMWF temperature and dew point temperature 
Table 2. Latitude and longitude boundaries in decimals for the investigated areas.

\begin{tabular}{lllll}
\hline & $\begin{array}{l}\text { Min } \\
\text { latitude }\end{array}$ & $\begin{array}{l}\text { Max } \\
\text { latitude }\end{array}$ & $\begin{array}{l}\text { Min } \\
\text { longitude }\end{array}$ & $\begin{array}{l}\text { Max } \\
\text { longitude }\end{array}$ \\
\hline Vavihill & 55.9 & 56.7 & 13 & 14 \\
Hyytiälä & 61.51 & 62.51 & 23.78 & 24.95 \\
\hline
\end{tabular}

at $2 \mathrm{~m}$ were acquired to calculate the lifting condensation level (LCL). The ECMWF meteorological parameters have all been obtained at 12:00 UTC.

Back trajectories calculated using Hysplit4 (Draxler and Hess, 1997) were used to determine origin of the air masses. The meteorological data employed in these calculations are from the National Centre of Environmental Predictions (NCEP) GDAS (Global Data Assimilation System). A centre of gravity has been calculated for 72 hour back trajectories and the azimuth and distance from the station to the centre of gravity were derived.

\subsection{Precipitation data}

Precipitation data from ground-based meteorological stations, henceforth GBP, for the area surrounding Vavihill have been obtained from the Swedish Meteorological and Hydrological Institute (SMHI). The locations of the stations have varied somewhat over the years, but simultaneous data from at least 11 stations are available for the entire time period investigated. For the area around Hyytiälä, there are unfortunately not as many precipitation measurements available. Precipitation data from the SMEAR station itself have been used together with data from 3 FMI (Finish Meteorological Institute) stations. The data from the 2 of the 3 FMI stations do not cover the entire investigation period and hence this dataset is considerably smaller than that from Vavihill. The time resolution of both precipitation datasets is only on a daily basis. The GBP data for Vavihill is measured from 06:00 local standard time to 06:00 the next morning, while at Hyytiälä the measurements are from 08:00 to 08:00 the next day.

Weather radar data have been obtained from the BALTEX (Baltic Sea Experiment) Radar Data Centre for both areas investigated in this study. Composite images from approximately $30 \mathrm{C}$-band weather radars in the Nordic countries, Poland and Germany are generated every 15 minutes (Michelson, 2006; Michelson and Sunhede, 2004). The images have a $2 \mathrm{~km}$ horizontal resolution and contain the reflectivity factor in $\mathrm{dBZ}$ (referred to as dbzc here). The same areas used in the analysis of the satellite data (Fig. 1) were analysed in the radar composite images. Ideally, the radar images could have been put on top of the satellite images to determine which clouds that were precipitating. However, since the coordinates of the images are obtained with different positioning systems the images may be shifted with respect to each other. In addition, since the radar images are generated every 15 minutes, there is a time lag between the radar and satellite observations, even though the lag is maximum 5 minutes. Hence the entire areas marked in Fig. 1 were used to compare the radar and satellite data. For the dbzc images, only the pixels containing precipitation were used to calculate an average rain rate for each scene. In addition to the dbzc data, $3 \mathrm{~h}$ accumulated precipitation ( $\mathrm{rr} 3 \mathrm{~h})$, generated 8 times per day from the radar data (Michelson et al., 2000; Koistinen and Michelson, 2002) has also been analysed here. The rr3h scene covering the time period to which the satellite scene belongs was used for each case. For the rr3h scenes, all pixels are used to calculate the average rain amount since it is interesting to investigate the mean amount of precipitation that has fallen in the entire region during $3 \mathrm{~h}$.

\subsection{Cloud profile retrievals}

The method to obtain vertical profiles of clouds from a satellite scene developed by Rosenfeld and Lensky (1998), where the $r_{\mathrm{e}}$ is plotted against the CTT, was applied in this study. This method assumes that convective clouds within a satellite image have cloud tops at different heights which represent clouds during different stages of their development. The validity of this assumption has been verified by both aircraft measurements (Freud et al., 2008a) and satellite measurements (Lensky and Rosenfeld, 2006). The 30th percentile of the variation in $r_{\mathrm{e}}$ with height has been studied here since this represents clouds early in their development, which are less influenced by ice formation (Freud et al., 2008b). The retrievals of $r_{\mathrm{e}}$ for ice pixels is more complicated than for water pixels due to the different shapes and sizes of ice particles (King et al., 1997). Since $r_{\mathrm{e}}$ is usually larger for ice pixels than water pixels, the 30th percentile profile is used to minimise overestimations of the $r_{\mathrm{e}}$ profile values due to uncertainties in the $r_{\mathrm{e}}$ from ice pixels. Similar results were however obtained when the median profile was used instead. The same procedure has been applied to COT data to obtain vertical profiles of this parameter.

Certain pixels have been removed from the dataset to ensure that the study focuses on convective clouds. If pixels have a COT less than 7, the $r_{\mathrm{e}}$ retrieval becomes uncertain due to possible surface contamination and therefore these pixels have been removed. Pixels containing cirrus clouds overlaying convective clouds have uncertain cloud retrievals and hence pixels flagged with a multilayer cloud flag were not included in the analysis either. Furthermore, single layers of cirrus clouds are also problematic since the COT seems to decrease with height when they are included in the profiles. Pixels with COT $<25$ and cirrus reflectance $>0.02$ have therefore also been removed before creating the profiles.

Once the profiles were created some further criteria were applied. For profiles containing vertical gaps greater than $7^{\circ} \mathrm{C}$, pixels at higher altitude in the clouds were removed from the profile. This was done to ensure that high level 
clouds in the satellite images, not connected to the cumulus cloud area were not included in the study. Moreover, only profiles with a vertical extent greater or equal to $9^{\circ} \mathrm{C}$ have been included in the study such that CTT varies significantly in the satellite scene, implying that the investigated clouds are indeed convective. The temperature at the LCL (Inman, 1969) was calculated from the ECMWF temperature and dew point temperature at $2 \mathrm{~m}$ and compared to the cloud base temperature $\left(T_{\mathrm{B}}\right)$ derived from MODIS data (assuming that the highest CTT within a satellite scene $+2{ }^{\circ} \mathrm{C}$ equals $T_{\mathrm{B}}$ ) to ensure that the clouds did not form at altitudes far greater than convective clouds could be anticipated at. Additionally, the $r_{\mathrm{e}}$ and COT are expected to increase with height in convective clouds and hence the profiles that do not fulfill this criteria are not included in the analysis.

Rosenfeld and Gutman (1994) used satellite and radar data to show that an $r_{\mathrm{e}}$ of $14 \mu \mathrm{m}$ can be seen as the threshold limit for where the cloud droplets become large enough to be influenced by coalescence processes and produce precipitation in warm convective clouds. The difference between $T_{\mathrm{B}}$ and the temperature where the $r_{\mathrm{e}}$ cloud profiles reaches $14 \mu \mathrm{m}$ $\left(\Delta T_{14}\right)$ is therefore a useful parameter to characterise the profiles with merely one number (Freud et al., 2008b; Lensky and Drori, 2007). Since not all clouds reach an $r_{\mathrm{e}}$ of $14 \mu \mathrm{m}$ the number of cases used in the analysis of this parameters is somewhat less than for the other parameters.

\section{Results}

In total, 388 profiles from Vavihill and 295 from Hyytiälä fulfill all the criteria described above and are included in the study. Table 3 shows the number of days included in each step of the analysis. MODIS $r_{\mathrm{e}}$ data were not always available during days with DMPS data since the retrieval requires daylight which is not always present at the satellite overpass over these regions in winter. This is especially noticeable in the number of days excluded for Hyytiälä station which is located further north. At both stations, only about half of the scenes containing convection were included as profiles in the study. Many scenes were excluded because the convection was too shallow to produce profiles with high enough vertical extent while other scenes contained contamination from non-convective cloud types and some may have been misclassifications of convective clouds.

The profiles are compared to each other by offsetting them with respect to $T_{\mathrm{B}}$. To determine which parameters affect the $r_{\mathrm{e}}$, the profiles have been sorted according to several different variables, not all shown here. Plotting all the profiles in one graph is not possible due to the large number of profiles and they were hence divided into 6 bins according to the chosen parameter, with approximately the same number of profiles in each bin. One profile for each bin was then obtained by calculating a median value of all profiles in the bin for each
Table 3. Number of days in different steps of the data analysis. The columns from left to right show the number of days with: DMPS data, DMPS data and MODIS scenes simultaneously, convection present in the scene according to the manual investigation of the scenes and approved profiles included in the study.

\begin{tabular}{lllll}
\hline & DMPS & $\begin{array}{l}\text { DMPS } \\
\text { MODIS }\end{array}$ & Convection & Profiles \\
\hline Vavihill & 2180 & 2129 & 800 & 388 \\
Hyytiälä & 3588 & 2863 & 500 & 295 \\
\hline
\end{tabular}

temperature level. Moreover, at least 7 profile values were required at each level for a median value to be calculated.

The aerosol and trajectory parameters have been averaged over $5 \mathrm{~h}$, centred at the time of the satellite overpass. However, using daily or daytime averaging instead did not affect the results to a large extent.

\section{Air mass origin and seasonal variability}

The back trajectory analysis suggests that air masses arriving from the south to Vavihill and Hyytiälä generally contain higher particle number concentrations than air masses arriving from other directions (Fig. 2a, b). These events with high number concentrations do however not occur very frequently and the high amount of aerosol particles are expected since air masses that arrive from the south pass over areas with substantial anthropogenic emissions. Westerly air masses are very dominant at Vavihill while at Hyytiälä there is a larger directional variation and most air masses arrive from the southwest or north. The meteorological parameters for Vavihill do not seem to vary significantly with air mass origin (Fig. 2c, e, g). At Hyytiälä however, the $T_{\mathrm{B}}$ and $\mathrm{SH}$ (Fig. 2d, h) are higher in southerly air masses, similar to the aerosol number concentrations in Fig. $2 b$.

The meteorological parameters vary significantly with season, see Fig. 3c-h. The $T_{\mathrm{B}}$, CAPE and the SH show clear annual variation, with higher values in summer. There is also an annual variation in particle number concentrations in Hyytiälä (Fig. 2b), while for at Vavihill the concentrations are more consistent during the year (Fig. 2a). That the particle number concentrations in Hyytiälä are generally higher in summer indicates that $N_{80}$ is influenced by biogenic secondary organic aerosols (BSOA), which reach high concentrations during this season (Kulmala et al., 2011; Leaitch et al., 2011). This is further supported by the relatively strong correlation between $N_{80}$ and the ECMWF reanalysis $2 \mathrm{~m}$ temperature for Hyytiälä $(r=0.64)$. Additionally, the $T_{\mathrm{B}}$ and $N_{80}$ are better correlated in Hyytiälä than in Vavihill (Table 4). 
Table 4. Correlation coefficients for Vavihill (top right) and Hyytiälä (bottom left). $N_{80}\left(\mathrm{~cm}^{-3}\right)$ is the number concentration of particles with a diameter above $80 \mathrm{~nm}, T_{\mathrm{B}}\left({ }^{\circ} \mathrm{C}\right)$ is the cloud base temperature, $d T\left({ }^{\circ} \mathrm{C}\right)$ is the temperature difference between cloud base and cloud top, CAPE $\left(\mathrm{J} \mathrm{kg}^{-1}\right)$ is the convective available potential energy, $w\left(\mathrm{Pas}^{-1}\right)$ is the vertical wind velocity, RH $(\%)$ is the relative humidity, $\mathrm{SH}\left(\mathrm{g} \mathrm{kg}^{-1}\right)$ is the specific humidity, $\Delta T_{14}\left({ }^{\circ} \mathrm{C}\right)$ is the temperature difference between the $r_{\mathrm{e}}$ profiles' cloud base and the $14 \mu \mathrm{m}$ level, GBP $\left(\mathrm{mm} \mathrm{day}^{-1}\right)$ is short for ground-based precipitation, dbzc is mean radar reflectivity factor $(\mathrm{dBZ})$ and $\mathrm{rr} 3 \mathrm{~h}$ is the accumulated precipitation between over a 3 hour interval retrieved from weather radars $(\mathrm{mm})$. The stars indicate at what confidence interval the correlation coefficients are significant.

\begin{tabular}{|c|c|c|c|c|c|c|c|c|c|c|c|}
\hline & $N_{\mathbf{8 0}}$ & $T_{\mathrm{B}}$ & $d T$ & CAPE & $w$ & $\mathrm{RH}$ & SH & $\Delta T_{14}$ & GBP & dbzc & $\begin{array}{l}\text { Vavihill } \\
\text { rr3h }\end{array}$ \\
\hline$N_{80}$ & $N_{80}$ & $0.26^{* * *}$ & $0.12^{*}$ & $0.13^{*}$ & $-0.16^{* *}$ & 0.00 & $0.20^{* * *}$ & $0.50^{* * *}$ & -0.03 & -0.07 & 0.02 \\
\hline$T_{\mathrm{B}}$ & $0.53^{* * *}$ & $T_{B}$ & $0.13^{* *}$ & $0.16^{* *}$ & -0.08 & 0.02 & $0.77^{* * *}$ & $0.30^{* * *}$ & 0.10 & 0.00 & 0.10 \\
\hline$d T$ & $0.17^{* *}$ & $0.17^{* *}$ & $d T$ & $0.42^{* * *}$ & $-0.36^{* * *}$ & $0.18^{* * *}$ & $0.27^{* * *}$ & $0.45^{* * *}$ & $0.38^{* * *}$ & $0.37^{* * *}$ & $0.53^{* * *}$ \\
\hline CAPE & 0.07 & $0.27^{* * *}$ & $0.38^{* * *}$ & CAPE & $-0.38^{* * *}$ & $0.17^{* *}$ & $0.42^{* * *}$ & $0.26^{* *}$ & $0.28^{* * *}$ & $0.18^{* *}$ & $0.37^{* * *}$ \\
\hline $\mathrm{w}$ & -0.10 & -0.05 & $-0.47^{* * *}$ & $-0.26^{* * *}$ & $\mathrm{w}$ & $-0.26^{* * *}$ & $-0.28^{* * *}$ & $-0.30^{* * *}$ & $-0.27^{* * *}$ & $-0.13^{*}$ & $-0.30^{* * *}$ \\
\hline RH & -0.05 & $0.39^{* * *}$ & $0.42^{* * *}$ & $0.39^{* * *}$ & $-0.36^{* * *}$ & $\mathrm{RH}$ & $0.25^{* * *}$ & 0.01 & $0.31^{* * *}$ & $0.29^{* * *}$ & $0.27^{* * *}$ \\
\hline $\mathrm{SH}$ & $0.48^{* * *}$ & $0.80^{* * *}$ & $0.34^{* * *}$ & $0.41^{* * *}$ & $-0.24^{* * *}$ & $0.65^{* * *}$ & SH & 0.11 & $0.30^{* * *}$ & $0.17^{* *}$ & $0.25^{* * *}$ \\
\hline$\Delta T_{14}$ & $0.50^{* * *}$ & $0.40^{* * *}$ & $0.49^{* * *}$ & 0.03 & $-0.20^{*}$ & 0.05 & $0.27^{* *}$ & $\Delta T_{14}$ & 0.09 & 0.14 & $0.20^{* * *}$ \\
\hline GBP & $0.16^{* *}$ & $0.15^{*}$ & $0.52^{* * *}$ & $0.25^{* * *}$ & $-0.38^{* * *}$ & $0.38^{* * *}$ & $0.33^{* * *}$ & $0.22^{*}$ & GBP & $0.30^{* * *}$ & $0.51^{* * *}$ \\
\hline dbzc & -0.10 & $-0.14^{*}$ & $0.49^{* * *}$ & $0.21^{* *}$ & $-0.22^{* * *}$ & $0.36^{* * *}$ & 0.12 & 0.16 & $0.27^{* * *}$ & dbzc & $0.47^{* * *}$ \\
\hline $\mathrm{rr} 3 \mathrm{~h}$ & 0.04 & 0.08 & $0.69^{* * *}$ & $0.21^{* *}$ & $-0.36^{* * *}$ & $0.50^{* * *}$ & $0.30^{* * *}$ & $0.27^{* *}$ & $0.61^{* * *}$ & $0.58^{* * *}$ & $\mathrm{rr} 3 \mathrm{~h}$ \\
\hline Hyytiälä & & & & & & & & & & & \\
\hline
\end{tabular}

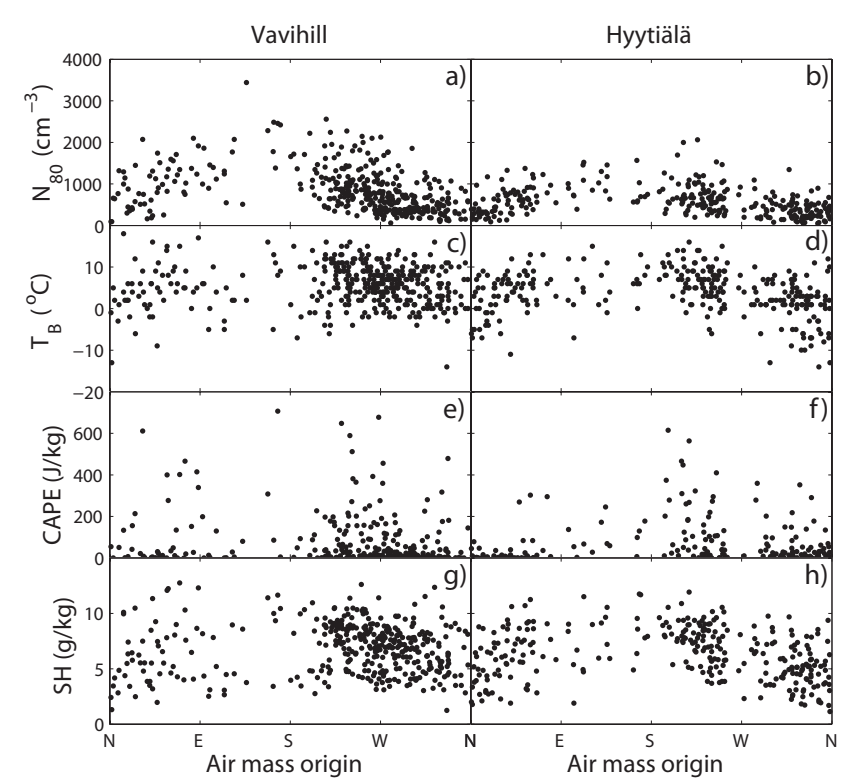

Fig. 2. The figure shows how the following parameters vary with air mass origin: $N_{80}$ (row 1), $T_{\mathrm{B}}$ (row 2), CAPE (row 3) and $\mathrm{SH}$ (row 4). The data from Vavihill is presented in column 1 and the data from Hyytiälä in column 2. $N_{80}$ is the number concentration of particles with a diameter above $80 \mathrm{~nm}, T_{\mathrm{B}}$ is the cloud base temperature, CAPE is the convective available potential energy and $\mathrm{SH}$ is the specific humidity at $1000 \mathrm{hPa}$. Only data from the 388 and 295 selected cloud scenes for Vavihill and Hyytiälä respectively, are shown.

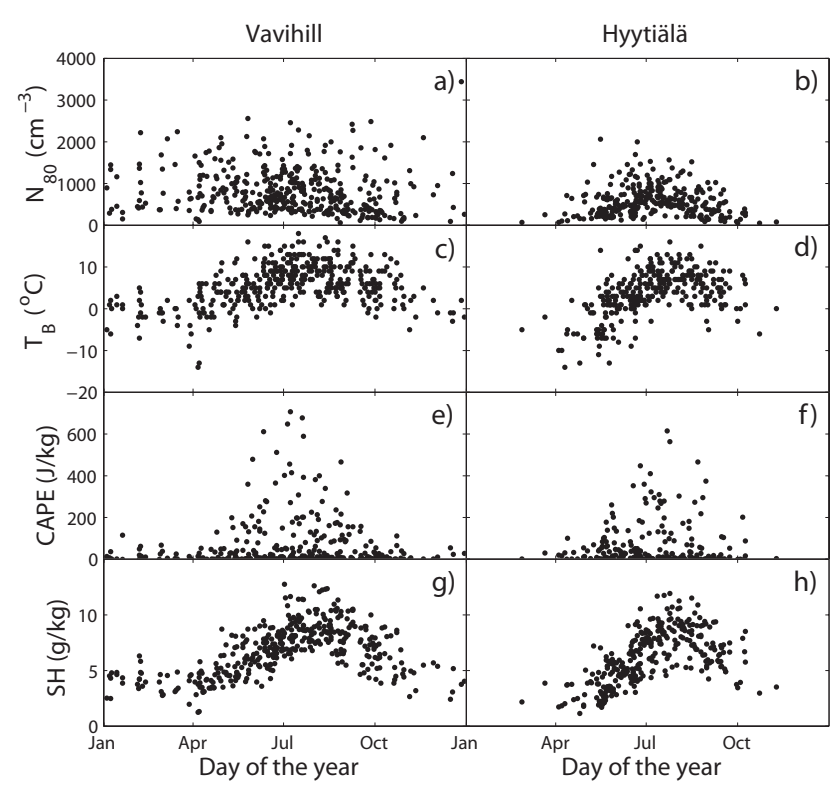

Fig. 3. The figure shows how the parameters in Fig. 2 vary over the year.

\subsection{Effective radius profiles}

Figure 4 shows the $r_{\mathrm{e}}$ profiles from Vavihill, Hyytiälä and both datasets combined, divided according to $N_{80}, T_{\mathrm{B}}$, CAPE and SH. It is clear that increased aerosol number concentrations are accompanied by decreased cloud droplet sizes at Vavihill, Hyytiälä and both stations combined (Fig. 4a-c). The profiles line up nicely with $N_{80}$ at almost all levels of 


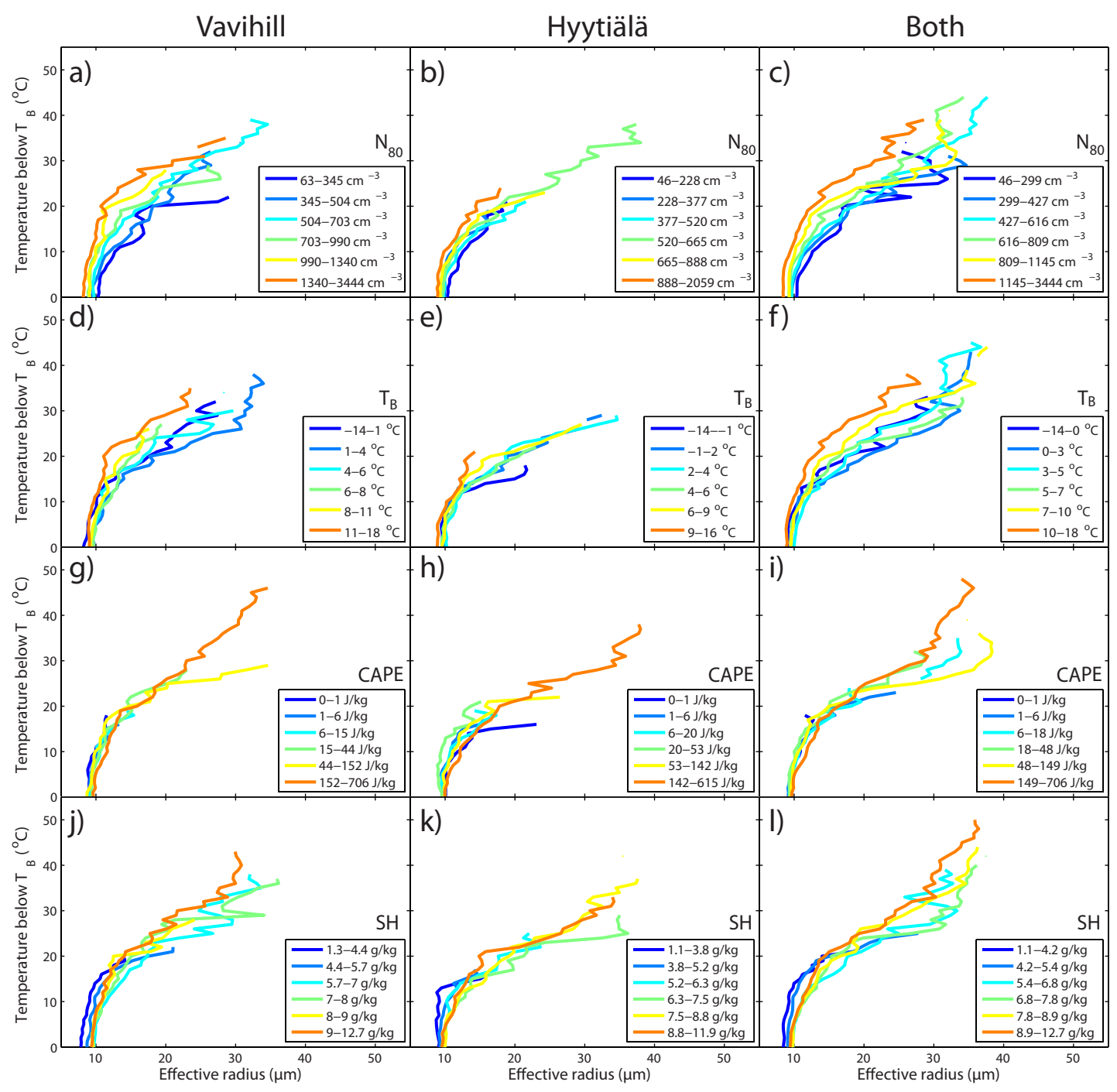

Fig. 4. Cloud effective radius is plotted as a function of temperature below that at cloud base to create vertical effective radius profiles. The figure shows average effective radius profiles for 6 percentiles of the data according to the $N_{80}$ (row 1), $T_{\mathrm{B}}$ (row 2), CAPE (row 3) and SH (row 4). The profiles from Vavihill are shown in column 1, from Hyytiälä in column 2 and both datasets combined are shown in column 3. $N_{80}$ is the number concentration of particles with a diameter above $80 \mathrm{~nm}, T_{\mathrm{B}}$ is the cloud base temperature, CAPE is the convective available potential energy and $\mathrm{SH}$ is the specific humidity at $1000 \mathrm{hPa}$.

the clouds, especially for the data from Vavihill. It has been investigated whether there is a statistically significant difference between the profiles according to a $t$ test with a $95 \%$ confidence interval. Every profile was compared to the other 5 profiles at each level of the profiles. For Fig. $4 a$, c, the profiles are statistically different from each other at most levels except when the profiles are compared to the profile from the closest intervals. For Fig. 4b statistical significant difference between the profiles occurs at most levels when the profiles two intervals away are compared. A previous study of convective clouds over southern Sweden, although only for one summer, also showed that clouds are sensitive to $\mathrm{PM}_{0.5}$ measured at ground-based stations (Freud et al., 2008b). Lin et al. (2006) created similar cloud profiles over South Amer- ica, but they sorted their profiles according to satellite retrieved AOD. The size of the $r_{\mathrm{e}}$ in their profiles did however not decrease with increasing AOD. In another study of cloud profiles, Koren et al. (2005) created vertical cloud profiles with the cloud top pressure on the $y$-axis instead of the CTT. This latter study covered clouds over the North Atlantic and showed that the $r_{\mathrm{e}}$ decreased with increasing AOD throughout the entire profiles, similar results to this study.

The $r_{\mathrm{e}}$ profiles at lower levels are not affected by the $T_{\mathrm{B}}$ which can be seen in Fig. $4 \mathrm{~d}-\mathrm{f}$. However, at 10 to $15^{\circ} \mathrm{C}$ colder than $T_{\mathrm{B}}$ when the $r_{\mathrm{e}}$ starts increasing faster with height, the warmer clouds have a smaller $r_{\mathrm{e}}$ than the colder clouds. This is most clearly visible when both datasets are used, Fig. $4 \mathrm{f}$, and is thought to be related to at which altitude 


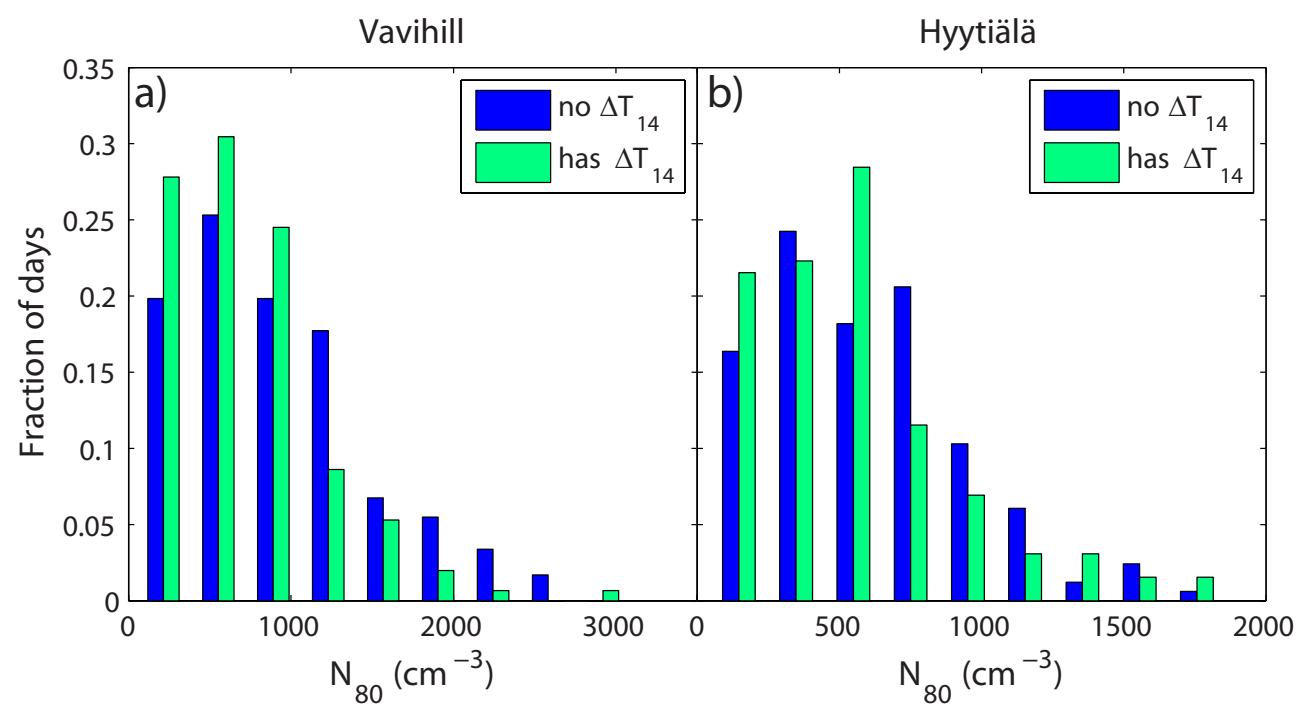

Fig. 5. Histogram of $N_{80}$ levels for cases with profiles that reach $14 \mu \mathrm{m}$ (has $\Delta T_{14}$ ) and profiles that do not reach $14 \mu \mathrm{m}$ (no $\Delta T_{14}$ ) for Vavihill (a) and Hyytiälä (b).

the clouds become mixed phase clouds. When the mixed phase is reached, coalescence and mixed-phase precipitation formation cause the $r_{\mathrm{e}}$ to start growing rapidly with height (Rosenfeld and Lensky, 1998). In Fig. 4d-f it is visible that the onset of this zone is dependent on the $T_{\mathrm{B}}$ since the profiles are separated at the cloud levels where the $r_{\mathrm{e}}$ starts growing from approximately $12 \mu \mathrm{m}$. The clouds with the highest $T_{\mathrm{B}}$ enter the mixed phase zone at the highest altitude above $T_{\mathrm{B}}$.

The profiles were also divided according to meteorological parameters from the ECMWF. The instability of the atmosphere does not seem to affect the droplet sizes in this dataset as can be seen in Fig. 4g, i. However, the cloud profiles do seem to be affected by the humidity at $1000 \mathrm{hPa}$. A lower SH results in smaller droplet sizes at lower levels of the profiles (Fig. 4j-1) and dividing the profiles according to $\mathrm{RH}$ produces similar results (not shown). The profiles were divided according to a few more parameters such as the $w$, the vertical extent of the profiles $(d T)$, the time the satellite image was retrieved, but since the profiles were not sensitive to these parameters the results are not shown here.

$\Delta T_{14}$ is the parameter that describes at what temperature below $T_{\mathrm{B}}$ that the $r_{\mathrm{e}}$ reaches $14 \mu \mathrm{m}$. The $\Delta T_{14}$ could be calculated for $40 \%$ of the $r_{\mathrm{e}}$ profiles at Vavihill, and for Hyytiälä this number was $44 \%$. The remaining profiles do not reach $14 \mu \mathrm{m}$. To investigate if the aerosols are suppressing the cloud droplet sizes and inhibiting the profiles from reaching an $r_{\mathrm{e}}$ of $14 \mu \mathrm{m}$, the histogram of $N_{80}$ for profiles that reach $14 \mu \mathrm{m}$ has been compared to the $N_{80}$ histogram for profiles which do not reach $14 \mu \mathrm{m}$, see Fig. 5. At Vavihill, Fig. 5a, the group of profiles that do not reach $14 \mu \mathrm{m}$ have a higher average (with a $99.9 \%$ confidence interval according to a Welch $t$ test) $N_{80}$ value than the group of profiles that do reach $14 \mu \mathrm{m}$. Hence, high aerosol number concentrations may prevent some profiles from reaching an $r_{\mathrm{e}}$ of $14 \mu \mathrm{m}$. The Hyytiälä distributions also indicate that $N_{80}$ is lower for the profiles with $\Delta T_{14}$ but the distributions are not significantly different from each other.

Table 4 can be used to investigate how $\Delta T_{14}$ is affected by cloud and meteorological parameters. $\Delta T_{14}$ is strongest correlated with $N_{80}$ and $d T$. Larger $\Delta T_{14}$ means that droplets need to reach higher altitudes to obtain an $r_{\mathrm{e}}$ of $14 \mu \mathrm{m}$, hence that the droplets are generally small. The positive correlations between $\Delta T_{14}$ and $N_{80}$ show that higher aerosol number concentrations result in smaller droplet sizes, just like the profile examination showed. The strong correlation between $\Delta T_{14}$ and $d T$ is expected since the vertical extent of the profile also limits the $\Delta T_{14}$ and this correlation is hence an artifact of the method. The $w$ is negatively correlated to $\Delta T_{14}$ which is also linked to the vertical extent of the profiles. Large negative values of $w\left(\mathrm{~Pa} \mathrm{~s}^{-1}\right)$ mean that there is a stronger upward motion of the atmosphere which favours greater vertical extent of the profiles. $T_{\mathrm{B}}$ is positively correlated with $\Delta T_{14}$ which is not surprising since a higher $T_{\mathrm{B}}$ elevate the level of the mixed-phase zone where $r_{\mathrm{e}}$ starts to grow rapidly.

The COT profiles were also divided according the same parameters but neither aerosols nor meteorological parameters were found to separate the profiles from each other to any great degree.

\subsection{Precipitation}

The $r_{\mathrm{e}}$ profiles have also been divided according to the mean amount of precipitation measured at ground level (Fig. 6ac), mean radar reflectivity factor (Fig. 6d-f) and mean $3 \mathrm{~h}$ accumulated precipitation calculated from radar data (Fig. $6 \mathrm{~g}$ i). The separation of the profiles according to the different 


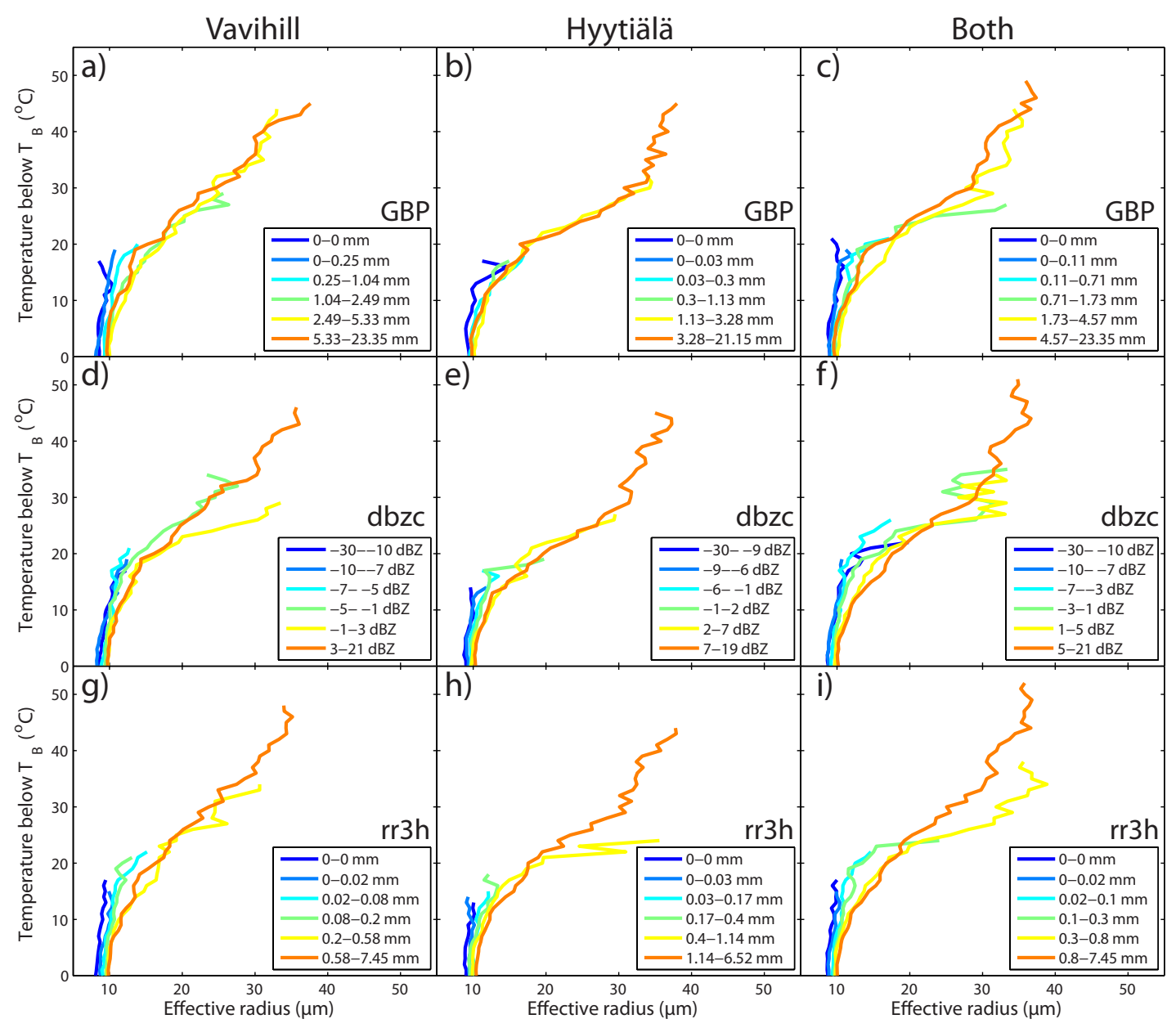

Fig. 6. Average effective radius profiles for 6 percentiles of the data according to the GBP (row 1), dbzc (row 2) and rr3h (row 3 ) for Vavihill (column 1), Hyytiälä (column 2) and both datasets combined (column 3). GBP is the ground-based precipitation accumulated over $24 \mathrm{~h}$, dbzc is the reflectivity factor from ground-based weather radars and the $\mathrm{rr} 3 \mathrm{~h}$ is the accumulated precipitation for a $3 \mathrm{~h}$ period from the weather radars.

precipitation datasets display quite similar results. Profiles with no or almost no precipitation have smaller droplet sizes and smaller vertical extent compared to cases with precipitation. Furthermore, for profiles that produce no or very little precipitation, the mixed-phase zone is not visible since there is no strong increase in $r_{\mathrm{e}}$ with height.

In Table 4, the correlation coefficients for the precipitation parameters are shown. The $d T$, CAPE, $w, \mathrm{RH}$ and SH have the strongest correlations with the precipitation parameters at both stations and all have positive correlations except $w$. Only low, hardly significant correlations with different signs are found between $N_{80}$ and the precipitation parameters. The meteorological conditions hence control the amount of precipitation, rather than aerosol number concentrations. The strongest correlations at both stations are between the precipitation parameters and $d T$ indicating that the most important parameter for precipitation is the vertical extent of the clouds. This is expected since convective clouds which reach a greater altitude generally produce greater amount of precipitation than clouds with a lower vertical extent. $d T$ is calculated by taking the temperature difference between the warmest and coldest pixels included in the profile retrieval.

The precipitation parameters are barely significantly correlated with $\Delta T_{14}$ but all correlation coefficients are positive. However, when the precipitation amounts from the profiles that do not reach $14 \mu \mathrm{m}$ are compared to those that do, it is clear that profiles with a $\Delta T_{14}$ produce more precipitation that those without (Fig. 7). This supports the results by Rosenfeld and Gutman (1994) that $14 \mu \mathrm{m}$ is a useful threshold to estimate if warm clouds are precipitating.

Previous studies have found that the response of the precipitation to droplet number concentrations and condensation nuclei depends on the LWP of the clouds (Sorooshian et al., 2009; Li et al., 2011), but when this dataset was divided according to a geometrical average LWP for each scene, no significant difference in the correlations between the aerosol 

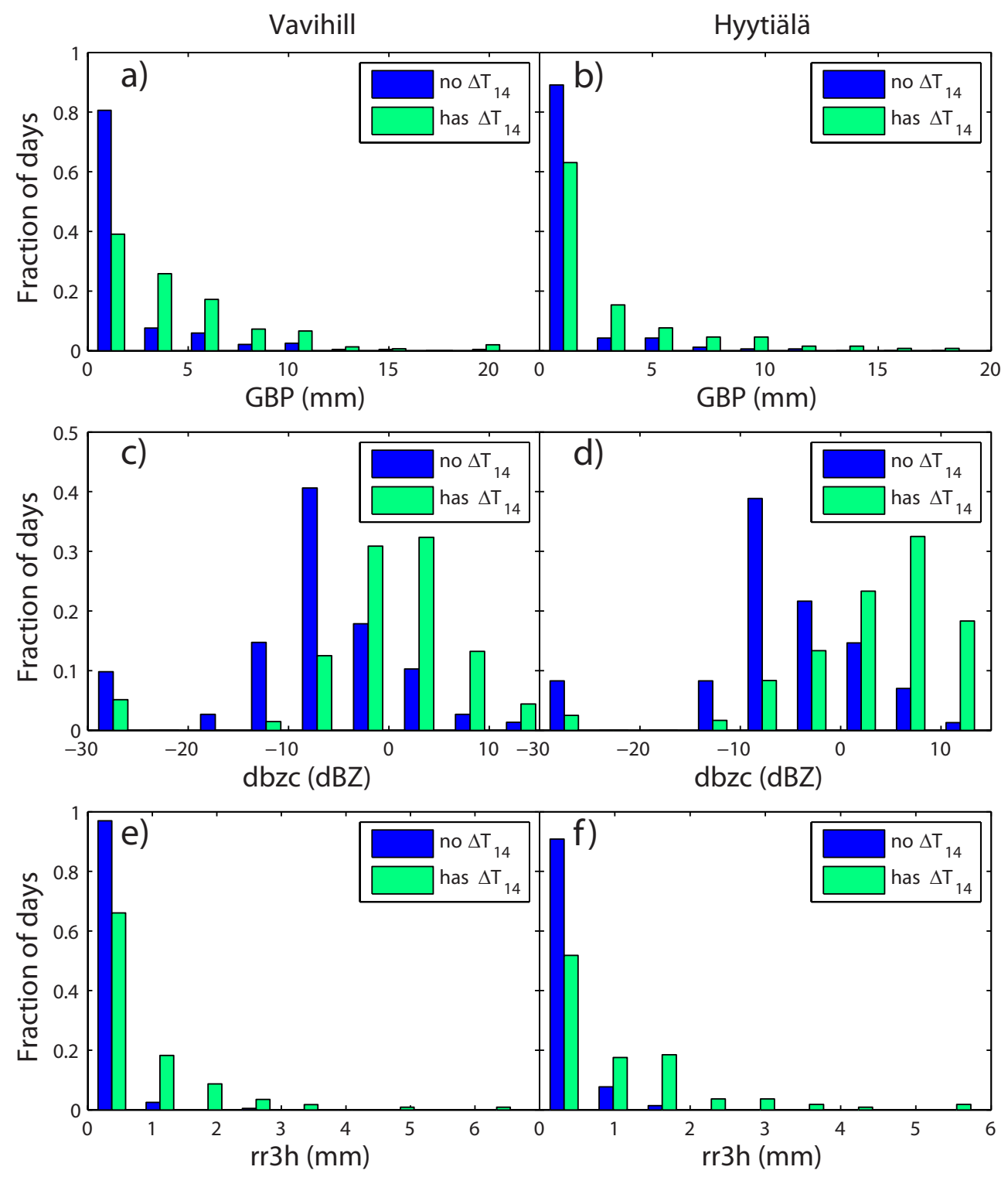

Fig. 7. Histograms of the amount of ground-based precipitation accumulated over 24 hours (a and b), reflectivity factor from ground-based weather radars ( $c$ and $d$ ) and the accumulated precipitation for a $3 \mathrm{~h}$ period from the weather radars (e and $\mathbf{f}$ ) for cases with profiles that reach $14 \mu \mathrm{m}$ (has $\Delta T_{14}$ ) and profiles that do not reach $14 \mu \mathrm{m}$ (no $\Delta T_{14}$ ). The figures on the left (a, $\left., \mathbf{e}, \mathbf{e}\right)$ are for the Vavihill dataset and $(\mathbf{b}, \mathbf{d}, \mathbf{f})$ are for the Hyytiälä dataset.

and precipitation parameters was found. There are however strong positive correlations between the LWP and precipitation. Modelling studies have found that how the clouds respond to aerosol number concentrations depend on factors such as vertical wind velocities (Fan et al., 2009), RH near the surface (Khain et al., 2008) and CAPE (Lee et al., 2010). The data was divided into subsets according to these parameters but no significant changes in the way the aerosols affected the precipitation was found.

However, when the data is divided into 4 intervals of $d T$, the negative correlation between dbzc and $N_{80}$ increase in magnitude which can be seen $n$ Fig. $8 \mathrm{a}-\mathrm{c}$ and Table 5. If the days when there is no precipitation detected by the radars are omitted the negative correlations become even stronger and most intervals have significant correlations (solid lines) which is shown in Fig. 8d-f. In Table 5, the upper part of the table where the cases with no precipitation is included $42 \%$ of the correlations are significant while in the bottom part where the non-precipitation cases are omitted $67 \%$ of the correlations are significant. Since there is a large gap in the dbcz-values between the precipitating cases and nonprecipitating cases, the results in the lower part of the table are the ones that should be primarily studied. There is a lot of scatter in the data but the results indicate that higher $N_{80}$ 


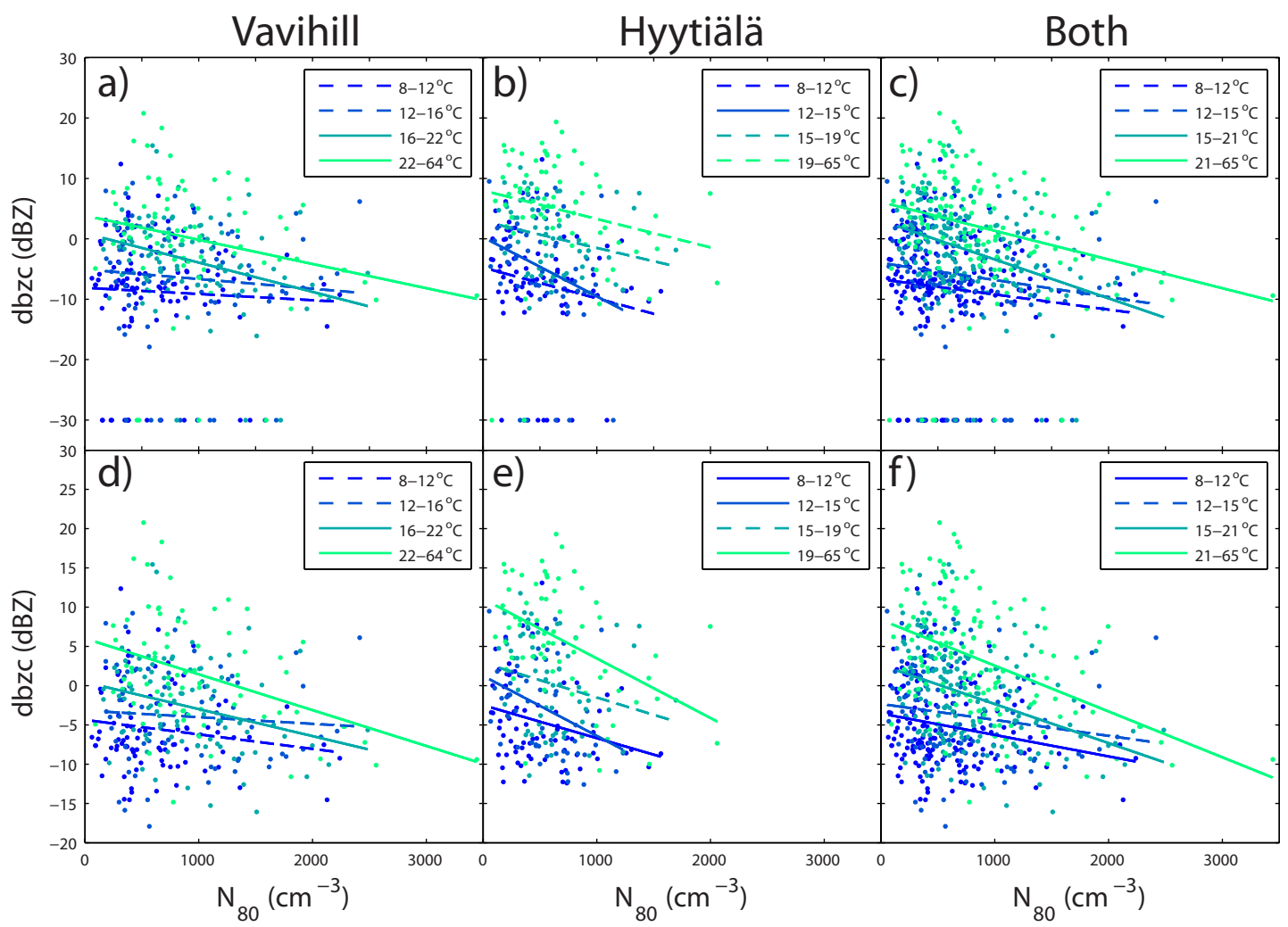

Fig. 8. Radar reflectivity vs. aerosol number concentrations for particles with a diameter greater than $80 \mathrm{~nm}$ for Vavihill (a and d), Hyytiälä (b and $\mathbf{e}$ ) and both datasets combined (c and $\mathbf{f}$ ). Each dataset has been divided into 4 subsets according to $d T$ and a trend line calculated for each dataset. Shown in the legend are the limits of $d T$ for each subset. Lines that are solid have a $p$ value smaller than 0.05 while dashed lines have a $p$ value greater than 0.05. $p$ values below 0.05 mean that the correlation is significant with a $95 \%$ confidence interval. Days when there is no precipitation detected by the radars are included in subfigures (a-c) and omitted in subfigures (d-f).

is associated with lower precipitation intensity. The clouds with the highest $d T$ are associated with the most intense precipitation and these clouds also seem to be most sensitive to aerosol effects since they show the greatest decrease in radar reflectivity with increasing $N_{80}$.

\section{Discussion and summary}

The aim of this study was to investigate how convective clouds over Scandinavia are affected by boundary layer aerosol particles. The profile and correlation analysis show that $r_{\mathrm{e}}$ is sensitive to the aerosol number concentration measured at ground level. Varying particle number concentration affects the clouds from the base throughout the vertical extent of the profiles since the profiles line up nicely according to $N_{80}$ at all levels (Fig. $4 \mathrm{a}-\mathrm{c}$ ). The difference between the profiles divided according to $N_{80}$ for Vavihill is larger than those for Hyytiälä (Fig. 4a, b). This is in line with the magnitude and spread of $N_{80}$, which is greater at Vavihill than at Hyytiälä. The four middle $N_{80}$ intervals at Hyytiälä only differ by approximately 600 particles $\mathrm{cm}^{-3}$ while at Vavihill this number is almost 1000 . There is also a stronger posi- tive correlation between $N_{80}$ and $\mathrm{SH}$ at Hyytiälä (Table 4) which could mask some of the effect the aerosols have on the droplets. A low SH can reduce the size of the droplets as can be seen in Fig. $4 \mathrm{j}-1$. However, the different sensitivities to $N_{80}$ could also be caused by dissimilarities in the aerosol particle properties between the two stations. Vavihill is situated more closely to continental Europe with more anthropogenic aerosol emissions while Hyytiälä is more affected by BSOA (Kerminen et al., 2012). That these BSOA are not as efficient $\mathrm{CCN}$ as the more aged anthropogenic particles (Kulmala et al., 2011) at Vavihill could also explain the variation in how much the aerosols affect the $r_{\mathrm{e}}$ between the two stations.

None of the meteorological parameters that we have investigated here seem to affect the $r_{\mathrm{e}}$ profiles as much as the aerosol particles do, even though the cloud base temperature affect at what height the clouds reach the mixed phase. As mentioned previously, the SH does affect the droplet sizes, especially at lower $\mathrm{SH}$ where the droplet sizes are reduced. The entire effect of the SH may not be visible in the data because of the positive correlation with $N_{80}$.

Studying convective clouds using satellite retrievals that assume plane-parallel clouds introduces uncertainties in the 
Table 5. Slopes of trend lines in Fig. $8 \pm$ the $95 \%$ confidence intervals of the slopes, correlation coefficients and $p$ values for the $d T$ intervals $\left({ }^{\circ} \mathrm{C}\right)$ in Fig. 8. The non-shaded part of table is values for the dataset including zero-values of dbcz and shaded part of table are for the dataset without zero-values of dbcz.

\begin{tabular}{llllllllllll}
\hline Vavihill & \multicolumn{1}{c}{ Hyytiälä } & \multicolumn{9}{c}{ Both } \\
\hline$d T$ interval & Slope $\times 10^{4}$ & $r$ & $P$ & $d T$ interval & Slope $\times 10^{4}$ & $r$ & $p$ & $d T$ interval & Slope $\times 10^{4}$ & $r$ & $p$ \\
$8-12$ & $-10.3 \pm 43$ & -0.05 & 0.64 & $8-12$ & $-51.0 \pm 60$ & -0.18 & 0.10 & $8-12$ & $-25.1 \pm 34$ & -0.11 & 0.15 \\
$12-16$ & $-16.0 \pm 39$ & -0.09 & 0.42 & $12-15$ & $-97.8 \pm 81$ & -0.30 & 0.02 & $12-15$ & $-28.2 \pm 34$ & -0.14 & 0.11 \\
$16-22$ & $-48.5 \pm 31$ & -0.31 & 0.00 & $15-19$ & $-44.1 \pm 46$ & -0.24 & 0.06 & $15-21$ & $-64.3 \pm 23$ & -0.39 & 0.00 \\
$22-64$ & $-40.0 \pm 35$ & -0.25 & 0.02 & $19-65$ & $-47.1 \pm 50$ & -0.22 & 0.07 & $21-65$ & $-47.5 \pm 28$ & -0.27 & 0.00 \\
$8-12$ & $-18.5 \pm 25$ & -0.15 & 0.15 & $8-12$ & $-42.0 \pm 35$ & -0.27 & 0.02 & $8-12$ & $-27.3 \pm 20$ & -0.21 & 0.01 \\
$12-16$ & $-8.4 \pm 25$ & -0.08 & 0.51 & $12-15$ & $-76.4 \pm 53$ & -0.37 & 0.01 & $12-15$ & $-20.3 \pm 23$ & -0.16 & 0.08 \\
$16-22$ & $-34.4 \pm 25$ & -0.28 & 0.01 & $15-19$ & $-44.1 \pm 46$ & -0.24 & 0.06 & $15-21$ & $-49.8 \pm 19$ & -0.37 & 0.00 \\
$22-64$ & $-45.6 \pm 24$ & -0.40 & 0.00 & $19-65$ & $-75.9 \pm 36$ & -0.46 & 0.00 & $21-65$ & $-58.4 \pm 20$ & -0.44 & 0.00 \\
\hline
\end{tabular}

$r_{\mathrm{e}}$ which can be overestimated in cloud fields with much subpixel scale variability (Zhang et al., 2012). Low cloud fractions also introduce uncertainties in the $r_{\mathrm{e}}$ retrievals of cumulus clouds compared to, for example, stratocumulus clouds. 3-D effects such as shadowing and illumination can also be a problem when studying convective clouds (Vant-Hull et al., 2007) especially for high solar zenith angles that occur at the latitudes where this study takes place. Zhang et al. (2012) however found that both these problems are lesser for the $r_{\mathrm{e}}$ at $3.7 \mu \mathrm{m}$, used in this study, than for the $r_{\mathrm{e}}$ at $2.1 \mu \mathrm{m}$. To investigate if low zenith angles have affected the results presented here, the analysis was redone for June, July and August separately. This did however not alter the results considerably.

Freud et al. (2008a) found that higher ground based $\mathrm{PM}_{0.5}$ leads to higher cloud tops and Koren et al. (2005) also found that aerosol particles affect cloud top height using satellite based AOD. Li et al. (2011) on the other hand found that aerosol number concentrations only affect cloud top height for clouds with $T_{\mathrm{B}}$ warmer than $15^{\circ} \mathrm{C}$. Only very low correlations between $N_{80}$ and $d T$ was found in the present dataset (Table 4), which is in agreement with $\mathrm{Li}$ et al. (2011) since none of the clouds in this study have cloud bases warmer than $15^{\circ} \mathrm{C}$ (Fig. 2). $d T$ in our study is best correlated to CAPE and the vertical winds at $500 \mathrm{hPa}$. $d T$ is calculated by taking $T_{\mathrm{B}}$ minus the cloud top temperature and hence any uncertainty in $T_{\mathrm{B}}$ will be transferred to $d T$ and also to $\Delta T_{14} . T_{\mathrm{B}}$ is set to the warmest cloudy pixel $+2{ }^{\circ} \mathrm{C}$ and may be underestimated if no low clouds are present in the satellite scene. This is not believed to be common here since convective clouds usually have highly variable cloud top heights and clouds with $d T$ below $9{ }^{\circ} \mathrm{C}$ were excluded from the study.

The COT profiles investigated here were not separated from each other when divided according to $N_{80}$ even though the aerosol particles are associated with smaller the droplet sizes. The first indirect aerosol effect was hence not detected in these clouds. The cause for the missing effect on COT was not found in the meteorological parameters since none of these separated the profiles significantly either and will not be speculated on. Convective clouds often have a high COT and quite low cloud fractions and therefore the modifications in their reflective properties will not affect the incoming shortwave to the degree that it would for other cloud types such as stratocumulus clouds.

The precipitation results from the profile analysis showed that clouds with smaller droplets produce less precipitation, while the correlation analysis showed small or nonsignificant correlations between the precipitation parameters and $N_{80}$. Instead, dynamical and meteorological variables like $d T, w, \mathrm{RH}, \mathrm{SH}$ and also CAPE at Vavihill are more strongly correlated with the precipitation parameters (Table 4). However, when taking $d T$ into account, the increased $N_{80}$ is associated with a decrease the radar reflectivity, which is a measure of the precipitation intensity (Fig. 8). Clouds with a high $d T$ are generally more sensitive to $N_{80}$ (Table 4 ). The large scatter in the data in Fig. 8 is expected since precipitation rates from clouds formed in very different conditions are being compared.

The decrease in precipitation with increasing $N_{80}$ is not present for the other two precipitation datasets. This could be caused by the larger amount of small values in these two datasets which makes correlations harder to detect. It could also be due to the fact that these two datasets represent the accumulated precipitation over a longer time period and not the intensity. The aerosols may not reduce the total amount of precipitation produced by the clouds over longer time periods but still affect the precipitation rates. Most of these satellite and radar images are from early in the afternoon and it could be that the aerosols decrease the intensity at this time of the day but cause the clouds to grow taller and produce more precipitation later in the afternoon as has been observed in other studies (Andreae et al., 2004; Li et al., 2011; Koren et al., 2012). There is however only very low correlation between $d T$ and $N_{80}$ in this dataset which point against such an invigoration of the clouds by the aerosols.

It is remarkable that the profiles associated with little or no precipitation show no rapid growth in $r_{\mathrm{e}}$ with altitude and never reaches $14 \mu \mathrm{m}$ (Fig. 5) which is the limit for warm 
precipitation found by Rosenfeld and Gutman (1994). Moreover, that the mixed-phase zone is missing for the $r_{\mathrm{e}}$ profiles with no or little precipitation confirms that it is indeed mixedphase and ice processes that are responsible for the convective precipitation at these latitudes. The results in Fig. 7 also support previous work (Rosenfeld and Gutman, 1994) even though quite a few profiles without a $\Delta T_{14}$ are associated with radar echoes Fig. 7c, d. This could be explained by large variations in $r_{\mathrm{e}}$ and/or radar echoes within the scene, the choice of 30th percentile profiles rather than median profiles (Sect. 2.5) and that the dataset is not restricted to warm clouds.

This study combines a variety of datasets from groundbased measurements to satellite cloud retrievals and ECMWF model data which have surely contributed to the low correlation between the different parameters in Table 4 . Another reason for the low correlations is that clouds, and the environments that they form in, are highly variable systems affected by a range of parameters. The correlations found, often significant, are however encouraging and prove that these multi-platform approaches are very useful in investigations of clouds. The combination of datasets clearly shows that $r_{\mathrm{e}}$ profiles can be separated according to aerosol number concentrations measured at the ground and modelled meteorological parameters. Warm air can hold more moisture and in Table 4 it can be seen that the $T_{\mathrm{B}}$, which is a satellite derived parameter, correlate strongly with the $\mathrm{SH}$ at $1000 \mathrm{hPa}$, which is a model parameter. Furthermore, the precipitation datasets, from different platforms, all have significant correlations with parameters known to affect precipitation such as $d T$ (from satellite data) and RH (modelled parameter). These different datasets hence complement each other well and produce interesting results when combined.

In this investigation of convective clouds over Sweden and Finland, in conditions with low aerosol and dynamical forcing, decreasing droplets sizes throughout the vertical extent of the clouds are associated with increasing aerosol number concentrations. The aerosol particles were nonetheless, found to affect neither the COT profiles nor invigorate the clouds. The results also show that the meteorological parameters investigated here affect the cloud droplet sizes to a lesser degree than the aerosols. However, the meteorological parameters rather than aerosols control the total amount of precipitation that reaches the ground. The precipitation intensity is nevertheless decreased in the presence of higher aerosol number concentrations when clouds with similar vertical extent are compared. Performing a similar study with data from other stations with long term ground-based size distribution measurements in other meteorological and aerosol conditions would be very interesting. Moreover, it would also be very interesting to compare these results to cloud model simulations of convective clouds over this region.
Acknowledgements. This work was carried out with the support of the FP6 European Commission project European Supersites for Atmospheric Aerosol Research, EUSAAR, contract No. RII3-CT2006-026140, the European Integrated Project on Aerosol, Cloud, Climate and Air Quality Interactions, EUCAARI, contract number 036833-2, the European Seventh Framework Programme, ACTRIS (EU INFRA-2010-1.1.16-262254), Aerosols, Clouds, and Trace gases Research Infra Structure Network, the Strategic Research Programme MERGE, Modelling the Regional and Global Earth System, and Lund Centre for studies of Carbon Cycle and Climate Interaction - LUCCI. We also gratefully acknowledge the support by the Swedish Research Council and from the Nordic Council of Ministers for the Nordic Top-level Research initiative CRAICC: Cryosphere-atmosphere interactions in a changing Arctic climate.

The satellite data from the MODIS instruments have been supplied by the National Aeronautics and Space Agency and the modelled meteorological data was provided by the ECMWF. Groundbased precipitation data have been supplied by the Swedish Meteorological and Hydrological Institute (SMHI) and the Finish Meteorological Institute (FMI). The weather radar data have been supplied by the BALTEX radar data centre.

We are very grateful to Prof. Daniel Rosenfeld for his support during the data evaluation and to Dr. Itmar Lensky for assisting us in calculating the cloud top temperature. We would also like to thank Daniel Michelson and the three anonymous reviewers for helpful comments on the manuscript.

Edited by: P. Stier

\section{References}

Aalto, P., Hämeri, K., Becker, E., Weber, R., Salm, J., Mäkelä, J., Hoell, C., O'Dowd, C., Karlsson, H., and Hansson, H.: Physical characterization of aerosol particles during nucleation events, Tellus B, 53, 344-358, 2001.

Albrecht, B. A.: Aerosols, Cloud Microphysics, and Fractional Cloudiness, Science, 245, 1227-1230, 1989.

Andreae, M., Rosenfeld, D., Artaxo, P., Costa, A., Frank, G., Longo, K., and Silva-Dias, M.: Smoking rain clouds over the Amazon, Science, 303, 1337-1342, 2004.

Andreae, M. O.: Correlation between cloud condensation nuclei concentration and aerosol optical thickness in remote and polluted regions, Atmos. Chem. Phys., 9, 543-556, doi:10.5194/acp-9-543-2009, 2009.

Asmi, A., Wiedensohler, A., Laj, P., Fjaeraa, A.-M., Sellegri, K. Birmili, W., Weingartner, E., Baltensperger, U., Zdimal, V., Zikova, N., Putaud, J.-P., Marinoni, A., Tunved, P., Hansson, H.C., Fiebig, M., Kivekäs, N., Lihavainen, H., Asmi, E., Ulevicius, V., Aalto, P. P., Swietlicki, E., Kristensson, A., Mihalopoulos, N., Kalivitis, N., Kalapov, I., Kiss, G., de Leeuw, G., Henzing, B., Harrison, R. M., Beddows, D., O’Dowd, C., Jennings, S. G., Flentje, H., Weinhold, K., Meinhardt, F., Ries, L., and Kulmala, M.: Number size distributions and seasonality of submicron particles in Europe 2008-2009, Atmos. Chem. Phys., 11, 5505-5538, doi:10.5194/acp-11-5505-2011, 2011.

Draxler, R. and Hess, G.: Description of the HYSPLIT_4 modeling system, NOAA Technical Memorandum ERL ARL-224, 24, 1997. 
Ekman, A., Engström, A., and Wang, C.: The effect of aerosol composition and concentration on the development and anvil properties of a continental deep convective cloud, Q. J. Roy. Meteor. Soc., 133, 1439-1452, 2007.

Fan, J., Yuan, T., Comstock, J., Ghan, S., Khain, A., Leung, L., Li, Z., Martins, V., and Ovchinnikov, M.: Dominant role by vertical wind shear in regulating aerosol effects on deep convective clouds, J. Geophys. Res., 114, D22206, doi:10.1029/2009JD012352, 2009.

Fors, E. O., Swietlicki, E., Svenningsson, B., Kristensson, A., Frank, G. P., and Sporre, M.: Hygroscopic properties of the ambient aerosol in southern Sweden - a two year study, Atmos. Chem. Phys., 11, 8343-8361, doi:10.5194/acp-11-8343-2011, 2011.

Freud, E., Rosenfeld, D., Andreae, M., Costa, A., and Artaxo, P.: Robust relations between $\mathrm{CCN}$ and the vertical evolution of cloud drop size distribution in deep convective clouds, Atmos. Chem. Phys., 8, 1661-1675, doi:10.5194/acp-8-1661-2008, 2008a.

Freud, E., Ström, J., Rosenfeld, D., Tunved, P., and Swietlicki, E.: Anthropogenic aerosol effects on convective cloud microphysical properties in southern Sweden, Tellus B, 60, 286-297, 2008 b.

Hansen, J., Sato, M., and Ruedy, R.: Radiative forcing and climate response, J. Geophys. Res.-Atmos., 102, 6831-6864, 1997.

Hari, P. and Kulmala, M.: Station for Measuring EcosystemAtmosphere relations, Boreal Environ. Res., 10, 315-322, 2005.

Inman, R. L.: Computation of Temperature at the Lifted Condensation Level, J Appl Meteorol, 8, 155-158, doi:10.1175/15200450(1969)008<0155:cotatl>2.0.CO;2, 1969.

Kerminen, V.-M., Paramonov, M., Anttila, T., Riipinen, I., Fountoukis, C., Korhonen, H., Asmi, E., Laakso, L., Lihavainen, H., Swietlicki, E., Svenningsson, B., Asmi, A., Pandis, S. N., Kulmala, M., and Petäjä, T.: Cloud condensation nuclei production associated with atmospheric nucleation: a synthesis based on existing literature and new results, Atmos. Chem. Phys., 12, 1203712059, doi:10.5194/acp-12-12037-2012, 2012.

Khain, A., Rosenfeld, D., and Pokrovsky, A.: Aerosol impact on the dynamics and microphysics of deep convective clouds, Q. J. Roy. Meteor. Soc., 131, 2639-2663, 2005.

Khain, A., BenMoshe, N., and Pokrovsky, A.: Factors determining the impact of aerosols on surface precipitation from clouds: An attempt at classification, J. Atmos. Sci., 65, 1721-1748, 2008.

Khain, A.: Notes on state-of-the-art investigations of aerosol effects on precipitation: a critical review, Environ. Res. Lett., 4, 015004 , 2009.

King, M., Menzel, W., Kaufman, Y., Tanré, D., Gao, B., Platnick, S., Ackerman, S., Remer, L., Pincus, R., and Hubanks, P.: Cloud and aerosol properties, precipitable water, and profiles of temperature and water vapor from MODIS, IEEE Trans. Geosci. Remote Sens., 41, 442-458, 2003.

King, M. D., Tsay, S. C., Platnick, S. E., Wang, M., and Liou, K. N.: Cloud retrieval algorithms for MODIS: Optical thickness, effective particle radius, and thermodynamic phase, MODIS Algorithm Theoretical Basis Document, 1997, 1997.

Koistinen, J. and Michelson, D. B.: BALTEX weather radar-based precipitation products and their accuracies, Boreal Environ. Res., 7, 253-263, 2002.

Koren, I., Kaufman, Y., Rosenfeld, D., Remer, L., and Rudich, Y.: Aerosol invigoration and restructuring of At- lantic convective clouds, Geophys. Res. Lett., 32, L14828, doi:10.1029/2005GL023187, 2005.

Koren, I., Altaratz, O., Remer, L. A., Feingold, G., Martins, J. V., and Heiblum, R. H.: Aerosol-induced intensification of rain from the tropics to the mid-latitudes, Nature Geosci., 5, 118-122, 2012.

Kristensson, A., Dal Maso, M., Swietlicki, E., Hussein, T., Zhou, J., Kerminen, V.-M., and Kulmala, M.: Characterization of new particle formation events at a background site in Southern Sweden: relation to air mass history, Tellus B, 60, 330-344, doi:10.1111/j.1600-0889.2008.00345.x, 2008.

Kulmala, M., Asmi, A., Lappalainen, H. K., Baltensperger, U., Brenguier, J.-L., Facchini, M. C., Hansson, H.-C., Hov, Ø., O'Dowd, C. D., Pöschl, U., Wiedensohler, A., Boers, R., Boucher, O., de Leeuw, G., Denier van der Gon, H. A. C., Feichter, J., Krejci, R., Laj, P., Lihavainen, H., Lohmann, U., McFiggans, G., Mentel, T., Pilinis, C., Riipinen, I., Schulz, M., Stohl, A., Swietlicki, E., Vignati, E., Alves, C., Amann, M., Ammann, M., Arabas, S., Artaxo, P., Baars, H., Beddows, D. C. S., BergstrÖm, R., Beukes, J. P., Bilde, M., Burkhart, J. F., Canonaco, F., Clegg, S. L., Coe, H., Crumeyrolle, S., D’Anna, B., Decesari, S., Gilardoni, S., Fischer, M., Fjaeraa, A. M., Fountoukis, C., George, C., Gomes, L., Halloran, P., Hamburger, T., Harrison, R. M., Herrmann, H., Hoffmann, T., Hoose, C., Hu, M., Hyvärinen, A., Hõrrak, U., Iinuma, Y., Iversen, T., Josipovic, M., Kanakidou, M., Kiendler-Scharr, A., Kirkevåg, A., Kiss, G., Klimont, Z., Kolmonen, P., Komppula, M., Kristjánsson, J.-E., Laakso, L., Laaksonen, A., Labonnote, L., Lanz, V. A., Lehtinen, K. E. J., Rizzo, L. V., Makkonen, R., Manninen, H. E., McMeeking, G., Merikanto, J., Minikin, A., Mirme, S., Morgan, W. T., Nemitz, E., O’Donnell, D., Panwar, T. S., Pawlowska, H., Petzold, A., Pienaar, J. J., Pio, C., Plass-Duelmer, C., Prévôt, A. S. H., Pryor, S., Reddington, C. L., Roberts, G., Rosenfeld, D., Schwarz, J., Seland, Ø., Sellegri, K., Shen, X. J., Shiraiwa, M., Siebert, H., Sierau, B., Simpson, D., Sun, J. Y., Topping, D., Tunved, P., Vaattovaara, P., Vakkari, V., Veefkind, J. P., Visschedijk, A., Vuollekoski, H., Vuolo, R., Wehner, B., Wildt, J., Woodward, S., Worsnop, D. R., van Zadelhoff, G.-J., Zardini, A. A., Zhang, K., van Zyl, P. G., Kerminen, V.-M., S Carslaw, K., and Pandis, S. N.: General overview: European Integrated project on Aerosol Cloud Climate and Air Quality interactions (EUCAARI) - integrating aerosol research from nano to global scales, Atmos. Chem. Phys., 11, 13061-13143, doi:10.5194/acp11-13061-2011, 2011.

Leaitch, W. R., Macdonald, A. M., Brickell, P. C., Liggio, J., Sjostedt, S. J., Vlasenko, A., Bottenheim, J. W., Huang, L., Li, S. M., and Liu, P. S. K.: Temperature response of the submicron organic aerosol from temperate forests, Atmos. Environ., 45, 6696-6704, 2011.

Lee, S. S., Donner, L. J., and Penner, J. E.: Thunderstorm and stratocumulus: how does their contrasting morphology affect their interactions with aerosols?, Atmos. Chem. Phys., 10, 6819-6837, doi:10.5194/acp-10-6819-2010, 2010.

Lensky, I. M. and Rosenfeld, D.: The time-space exchangeability of satellite retrieved relations between cloud top temperature and particle effective radius, Atmos. Chem. Phys., 6, 2887-2894, doi:10.5194/acp-6-2887-2006, 2006. 
Lensky, I. M. and Drori, R.: A satellite-based parameter to monitor the aerosol impact on convective clouds, J. Appl. Meteorol. Climatol., 46, 660-666, 2007.

Li, Z., Niu, F., Fan, J., Liu, Y., Rosenfeld, D., and Ding, Y.: Longterm impacts of aerosols on the vertical development of clouds and precipitation, Nature Geosci., 4, 888-894, 2011.

Lin, J., Matsui, T., Pielke Sr, R., and Kummerow, C.: Effects of biomass-burning-derived aerosols on precipitation and clouds in the Amazon Basin: a satellite-based empirical study, J. Geophys. Res., 111, D19204, doi:10.1029/2005JD006884, 2006.

Lohmann, U. and Feichter, J.: Global indirect aerosol effects: a review, Atmos. Chem. Phys., 5, 715-737, doi:10.5194/acp-5-7152005, 2005.

Michelson, D., Andersson, T., Koistinen, J., Collier, C., Riedl, J., Szturc, J., Gjertsen, U., Nielsen, A., and Overgaard, S.: BALTEX Radar Data Centre products and their methodologies, SMHI, Norrköping, Sweden, 76 pp., 2000.

Michelson, D.: The Swedish weather radar production chain, Proc. ERAD 2006, 2006.

Michelson, D. B. and Sunhede, D.: Spurious weather radar echo identification and removal using multisource temperature information, Meteorol. Appl., 11, 1-14, 2004.

Pincus, R. and Baker, M. B.: Effect of precipitation on the albedo susceptibility of clouds in the marine boundary layer, Nature, 372, 250-252, 1994.

Platnick, S., King, M. D., Ackerman, S. A., Menzel, W. P., Baum, B. A., Riedi, J. C., and Frey, R. A.: The MODIS cloud products: Algorithms and examples from Terra, IEEE Trans. Geosci. Remote, 41, 459-473, doi:10.1109/Tgrs.2002.808301, 2003.

Rosenfeld, D. and Gutman, G.: Retrieving microphysical properties near the tops of potential rain clouds by multispectral analysis of AVHRR data, Atmos. Res., 34, 259-283, 1994.
Rosenfeld, D. and Lensky, I.: Satellite-based insights into precipitation formation processes in continental and maritime convective clouds, B. Am. Meteorol. Soc., 79, 2457-2476, 1998.

Rosenfeld, D., Cattani, E., Melani, S., and Levizzani, V.: Considerations on Daylight Operation of 1.6-versus 3.7-mm Channel on NOAA and METOP Satellites, B. Am. Meteorol. Soc., 85, 873882,2004

Sihto, S.-L., Mikkilä, J., Vanhanen, J., Ehn, M., Liao, L., Lehtipalo, K., Aalto, P. P., Duplissy, J., Petäjä, T., Kerminen, V.-M., Boy, M., and Kulmala, M.: Seasonal variation of CCN concentrations and aerosol activation properties in boreal forest, Atmos. Chem. Phys., 11, 13269-13285, doi:10.5194/acp-11-13269-2011, 2011.

Sorooshian, A., Feingold, G., Lebsock, M. D., Jiang, H., and Stephens, G. L.: On the precipitation susceptibility of clouds to aerosol perturbations, Geophys. Res. Lett., 36, L13803, doi:10.1029/2009GL038993, 2009.

Stevens, B. and Feingold, G.: Untangling aerosol effects on clouds and precipitation in a buffered system, Nature, 461, 607-613, 2009.

Twomey, S.: Pollution and Planetary Albedo, Atmos. Environ., 8, 1251-1256, 1974.

Vant-Hull, B., Marshak, A., Remer, L. A., and Li, Z. Q.: The effects of scattering angle and cumulus cloud geometry on satellite retrievals of cloud droplet effective radius, IEEE T. Geosci. Remote, 45, 1039-1045, 2007.

Zhang, Z., Ackerman, A. S., Feingold, G., Platnick, S., Pincus, R., and Xue, H.: Effects of cloud horizontal inhomogeneity and drizzle on remote sensing of cloud droplet effective radius: Case studies based on large-eddy simulations, J. Geophys. Res. Atmos., 117, D19208, doi:10.1029/2012jd017655, 2012. 